
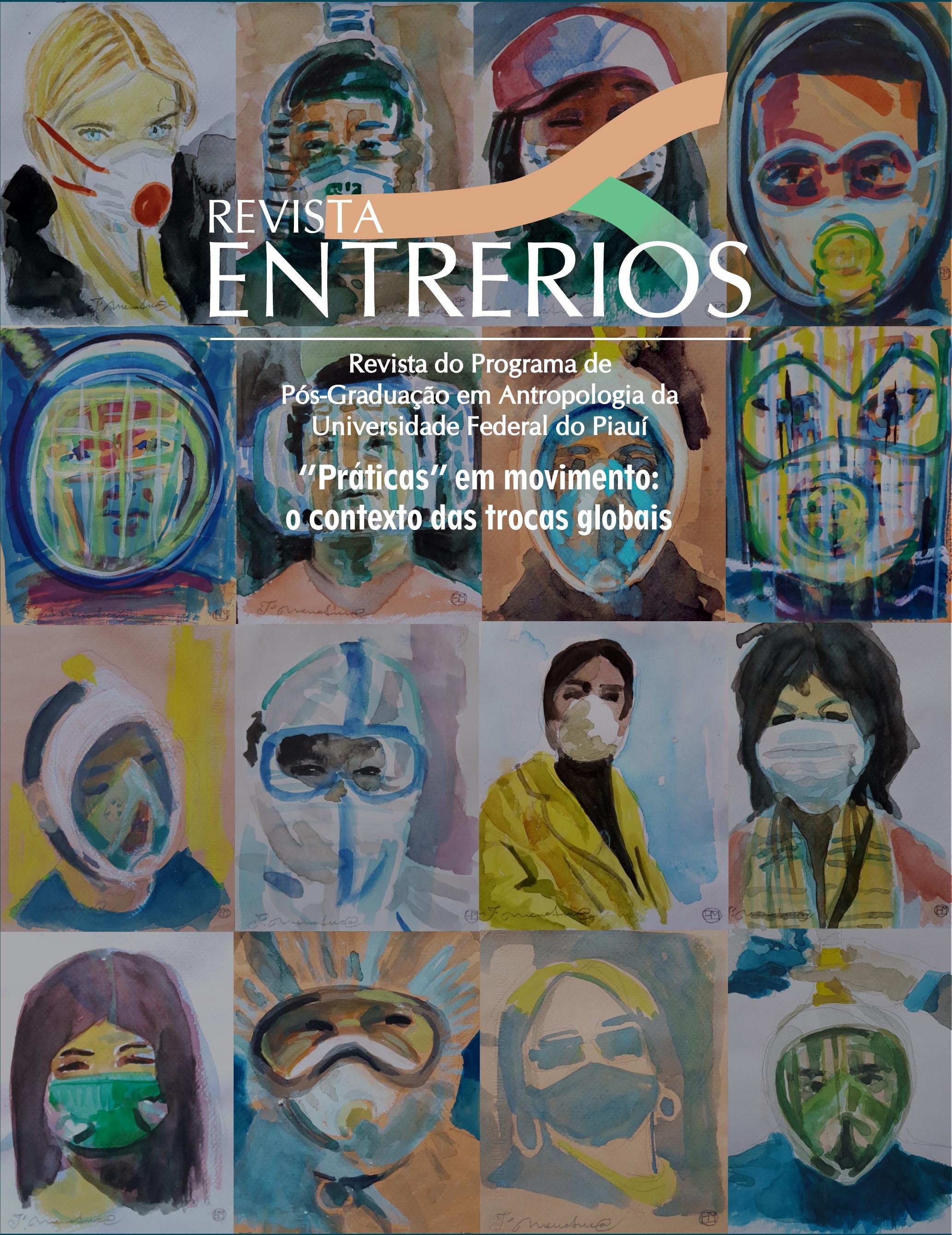

Celso de Brito

Daniel Granada

Monica Aceti

(Orgs.) 


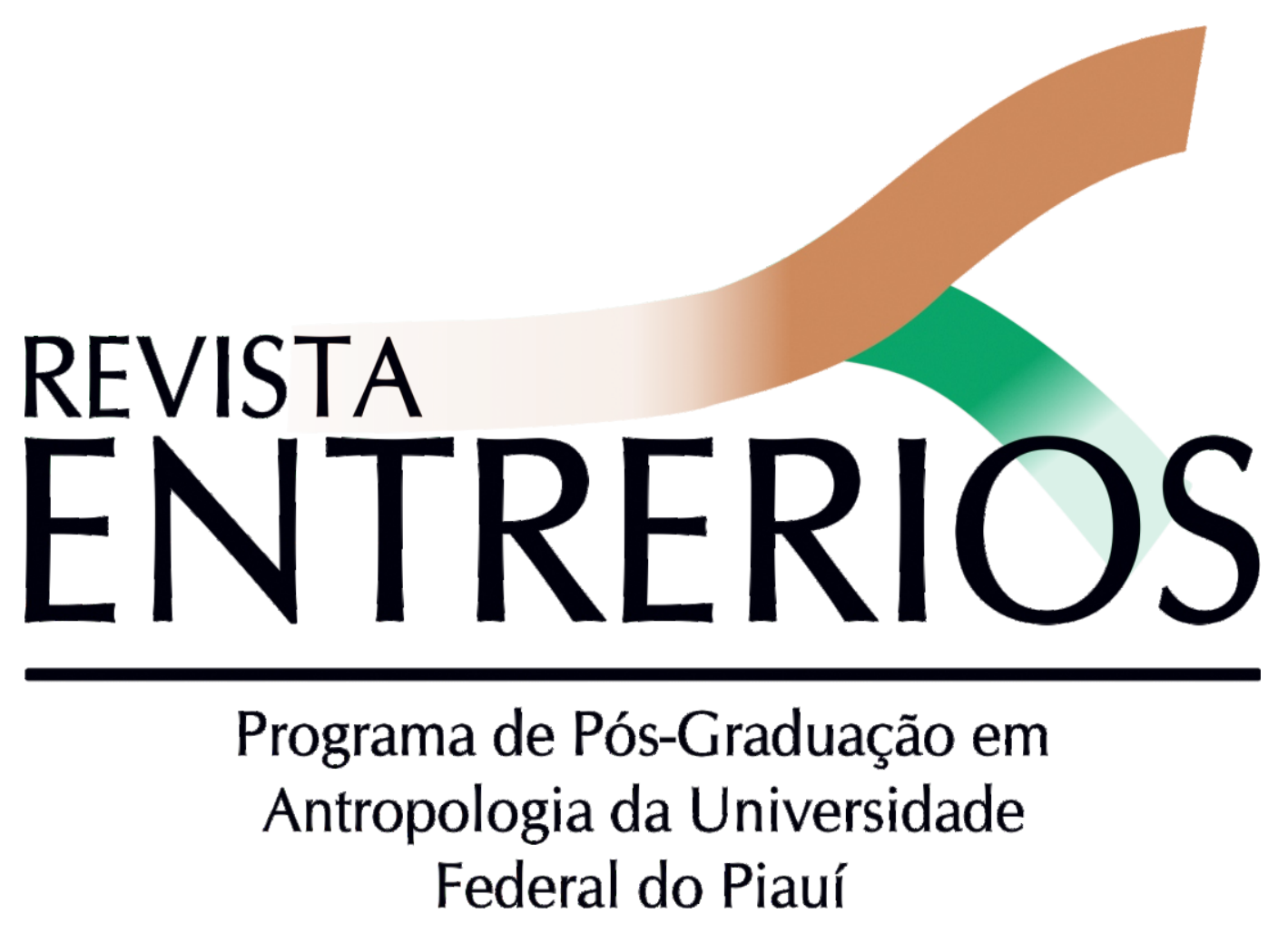

EntreRios - Revista do PPGANT - UFPI

Vol. 2, n. 2

Temática: "Práticas" em movimento:

o contexto das trocas globais

ISSN: 2595-3753

Teresina, 2019 


\author{
Reitor \\ Prof. Dr. José Arimatéia Dantas Lopes \\ Vice-Reitora \\ Profa Drạ Nadir do Nascimento Nogueira \\ Comissão Editorial (PPGANT - UFPI) \\ Alejandro Raul Gonzalez Labale \\ Andrea Lourdes Monteiro Scabello \\ Carlos Roberto Filadelfo de Aquino \\ Carmen Lúcia Silva Lima \\ Celso de Brito \\ Jóina Freitas Borges \\ Márcia Leila de Castro Pereira \\ Maria Lídia Medeiros de Noronha Pessoa \\ Mônica da Silva Araujo \\ Raimundo Nonato Ferreira do Nascimento \\ Conselho Editorial
}

Andréa Luisa Zhouri Laschefski - Universidade Federal de Minas Gerais (UFMG)

Alejandro Frigerio - Universidad Católica Argentina / CONICET

Christen Anne Smith - University of Texas at Austin (UT Austin)

Daniel Granada - Universidade Federal de Santa Catarina (UFSC)

Gabriel Maria Sala - Università Degli Studi di Verona

Joana Bahia - Universidade Estadual do Rio de Janeiro (UFRJ)

Laura Selene Mateos Cortez - Universidad Veracruzana - Xalapa - México (UV)

Leila Sollberger Jeolás - Universidade Estadual de Londrina (UEL)

Lorenzo Macagno - Universidade Federal do Paraná (UFPR)

Luis Roberto Cardoso de Oliveira - Universidade de Brasília (UNB)

Rosa Elisabeth Acevedo Marin - Universidade Federal do Pará (UFPA)

Editores Chefes

Carmen Lúcia Silva Lima

Raimundo Nonato Ferreira do Nascimento

Revisão

Os autores

Capa

Fernando Mendonça (Artista Plástico)

Diagramação

Antonio Andreson de Oliveira Silva

EntreRios - Revista do PPGANT -UFPI

Vol. 2, n.2 - Temática: "Práticas" em movimento:

o contexto das trocas globais 


\section{Sumário}

\section{APRESENTAÇÃO}

Práticas, culturas e mobilidades transnacionais

Celso de Brito/ Daniel Granada/ Monica Aceti 5

\section{ARTIGOS}

Esporte, portugalização e diáspora: os lusochineses de Moçambique

Lorenzo Macagno.

Trânsitos Transatlânticos: os orixás em Portugal

Joana Bahia

Trayectorias globales: movilidad, procesos identitarios y nuevos aprendizajes en la capoeira Angola

Sergio González Varela

É luta ou dança? Reinventando a capoeira na Bretanha francesa

Ricardo Nascimento

A web of orixás: Technology and the transmission of Candomblé songs in Bahia and Berlin

Nina Graeff

Circulations et réappropriations des enseignements du yoga moderne en France et en Suisse

Caroline Nizard

Skate Transnacional: difusão de performance e técnicas corporais em vídeo-partes

Giovanne Cirino

\section{ENTREVISTA}

O "afrocentrismo" e as voltas que o mundo dá: entrevista com Mestre Cobrinha Mansa

Celso de Brito/ Daniel Granada/ Matheus do Monte Marques/ Ricardo Nascimento.

\section{RESENHA}

GONZÁLEZ VARELA, Sergio Armando. Capoeira, mobility, and tourism: preserving an Afro-Brazilian tradition in a globalized world. Lanham: Lexington Books, 2019. 


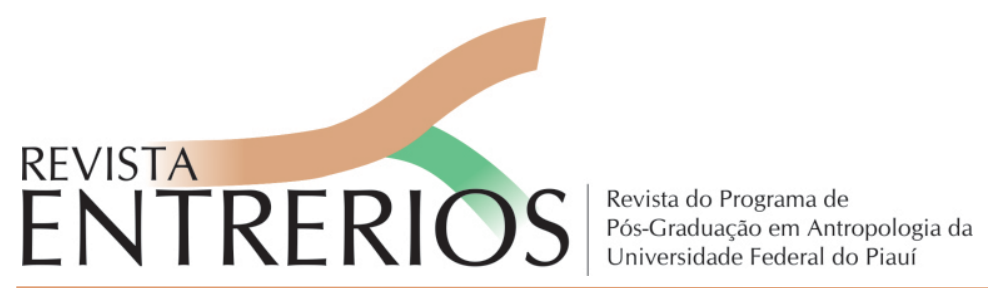

\title{
Práticas, culturas e mobilidades transnacionais
}

\author{
Celso de Brito \\ Universidade Federal do Piauí \\ celsodebrito@ufpi.edu.br \\ Daniel Granada \\ Universidade Federal de Santa Catarina \\ daniel.granada@ufsc.br \\ Monica Aceti \\ Universidade de Genebra \\ Monica.Aceti@unige.ch
}

A edição deste número da Revista EntreRios está sendo finalizada em um momento em que passamos por uma das maiores crises sanitárias da história da humanidade. No cenário internacional caótico da atualidade, estão sendo adotadas políticas nacionais de restrição de circulação de pessoas e o chamado "isolamento social". Mais uma vez, as tecnologias de controle de epidemias se relacionam com o controle dos corpos e com a ideia de se impor uma limitação de circulação e contatos. A chamada para este dossiê buscou colocar em evidência justamente o contrário: tornar explícitas as contribuições da Antropologia sobre o tema das práticas, dos corpos e suas técnicas em movimento, atravessando as fronteiras imaginárias das nações e se encontrando com outros praticantes em contextos diversificados.

Assim, mantendo a ideia fundamental de divulgar resultados de pesquisas que possam contribuir com o conjunto de produções científicas na Antropologia e áreas afins, o número 4 da Revista EntreRios apresenta trabalhos sobre as "'Práticas em movimento: o contexto das trocas globais". Tratam-se de pesquisas finalizadas sobre contextos transnacionais que enfatizam os fluxos, ora de especialistas, ora de objetos - como fotografias -, ora de ideias e técnicas via meios digitais e, consequentemente, os processos pelos quais esses elementos moldam novas configurações de práticas corporais ou novas elaborações identitárias. Os trabalhos aqui reunidos colocam em evidência a potência dos encontros, bem como a complexidade e a riqueza da circulação das práticas corporais.

No primeiro artigo, Lorenzo Macagno nos apresenta o processo de elaboração e reelaboração de identidades nacionais a partir da Associação de Basquete da comunidade de imigrantes chineses fixados em terras lusófonas (primeiramente em Moçambique e depois no Brasil). O autor parte da ideia de que "esporte" e "nação" formam "um par quase indissociável", a partir do qual foi possível analisar a mudança dos critérios definidores do que seria o "nacional" para os chineses do basquete em diáspora. 
Ora cidadãos chineses ora cidadãos portugueses ora cidadãos brasileiros... Algumas vezes inseridos e qualificados como "simpáticos", outras vezes rechaçados e qualificados como "agressivos", de acordo com distintos contatos históricos e políticos da referida diáspora.

A discussão apresentada por Joana Bahia no segundo artigo também trata do contexto lusófono. A antropóloga analisa o processo de transnacionalização do candomblé e sua consolidação em Portugal através de uma abordagem etnográfica interessante. Joana segue os passos do espírito Caboclo Pena Dourada para perceber as circularidades, adaptações e releituras da religião afro-brasileira em Portugal. A autora chamou sua abordagem de "Etnografia dos espíritos", isto é, "tomar como ponto de observação os efeitos e os produtos da possessão para seus praticantes". Além do conhecido continuum entre candomblé, umbanda e catolicismo popular em Portugal, Joana aponta um continuum entre a dimensão religiosa e a econômica nesse cenário. Em sua visão, trata-se de uma dimensão comercial na qual se encontram "diversas religiosidades qualificadas de New Age". Associadas a este "supermercado", Joana nos mostra as disputas pela legitimidade posta em marcha em torno da ideia de "pureza": ora o "candomblé puro" é associado aos pais de santo brasileiros, por serem estes responsáveis pela transmissão aos portugueses, ora é associado aos pais de santo portugueses, por estes estarem física e simbolicamente mais próximos da África, sobretudo devido ao "retorno" dos africanos pós-revolução de 1974.

A circulação, ou mais especificamente a "mobilidade", é assunto tratado por Sérgio Varela no terceiro artigo. Tomando o universo da capoeira angola e seus dois principais atores, o mestre e o discípulo, o antropólogo reflete sobre a relação entre o que chamou de "missionários culturais" (os mestres e contramestres brasileiros) e os "peregrinos de aprendizagem" (praticantes não brasileiros). Nesse cenário, a mesma intensidade que conduz os mestres a constantes viagens ao estrangeiro para ensinar orienta o fluxo de praticantes não brasileiros para fora de suas localidades, formando um "padrão de mobilidade múltiplo". Varela problematiza o encontro entre "missionários culturais" e "peregrinos de aprendizagem" tal qual a Antropologia problematiza o encontro entre antropólogos e seus interlocutores (o "outro"), ambas as relações marcadas por processos de invenção de realidades outras, de modo a serem assimiladas em sua própria. Varela nos mostra como discursos etnopolíticos ou religiosos têm incidido sobre o conceito de "tradição afro-brasileira" transmitido pelos mestres "missionários" nesse contexto de mobilidade transnacional, o que ocasiona equívocos de interpretação que acabam redefinindo o sentido atribuído à própria prática de capoeira angola como um todo.

Ricardo Nascimento também faz da capoeira seu objeto de análise, focando na relação entre capoeira e dança no quarto artigo deste número. Se o foco da análise precedente recai sobre o “mestre missionário" e o "discípulo peregrino", aqui a relação enfatizada é entre o "mestre de capoeira" e o "coreógrafo" - dois papéis sociais muitas vezes sobrepostos em uma mesma pessoa - durante a expansão da capoeira para o Oeste da França.

Ricardo nos mostra a capoeira sendo significada como uma prática artística e politizada, inserida numa cena artística forjada no nacionalismo bretão (Bretanha Francesa) e nela abrindo espaço para práticas culturais híbridas pós-coloniais. A capoeira descrita pelo antropólogo apresenta uma forma musical inusitada (com elementos inspirados no candomblé: gã e palmas que seguem o toque de "avamunha"), assim como influência de danças contemporâneas (inglesa e francesa: mais inteligíveis aos bretões). A circularidade/mobilidade também é apresentada por Ricardo como uma realidade absorvida pelo grupo estudado. Nele, é operacionalizado um sistema de graduações cujos critérios de ascensão são as próprias viagens, demonstradas publicamente pelas assinaturas e carimbos em seus passaporte, ou seja, a quantidade de carimbos de diferentes localidades e nacionalidades atesta a aquisição de conhecimento e justifica as posições dentro da hierarquia do grupo capoeira. 
Por fim, Ricardo defende a ideia de que a corporeidade na capoeira bretã torna claro que a capoeira representa um modelo social, uma forma de agir na sociedade pautada em "ajustes culturais entre lugares e pessoas, na sua dimensão política e social".

O candomblé e sua dinâmica transnacional também é o tema do quinto artigo, assinado por Nina Graeff, quem, através de trabalho de campo em terreiros de candomblé na Alemanha e no Brasil, nos mostra as linhas de convergência entre os seguidores europeus, latino-americanos, africanos e israelenses do Ilê Obá Silekê, de Berlim, e os filhos de santo de Pai Pote de Santo Amaro da Purificação, na Bahia. Tais linhas de convergência se dão, sobretudo, na necessidade e na dificuldade de aprender as cantigas rituais e as rezas na língua yorubá. A discussão ocorre em torno das tecnologias de aprendizagem utilizadas na transmissão do conhecimento do sagrado e seus diferentes sentidos e usos. Na Alemanha, mesmo tendo menos acesso ao conhecimento sagrado em suas vidas cotidianas, os candomblecistas tomam as tecnologias (escrita, gravação de áudio e internet) como "tabus"; enquanto os baianos "nascidos no candomblé", tendo amplo acesso às diversas redes sociais na comunidade de terreiros da cidade nas quais se mantém em circulação constante, utilizam a tecnologia (diários, gravações de áudios e vídeos na internet) sem nenhum melindre e sem oferecer perigo à sacralidade da religião ou à hierarquia existente no terreiro analisado.

No sexto artigo, Caroline Nizard analisa a dinâmica de hibridizações da yoga na Europa atual a partir das trajetórias de três professores cujas referências são as quatro linhagens tradicionais da "autêntica" yoga moderna. A antropóloga constrói sua pesquisa dividindo as formas com que as linhagens tradicionais se autodefinem, algumas mais espirituais e filosóficas, outras mais corporais e esportivas. Nizard nos mostra a lógica aparentemente contraditória entre "esporte/corpo" e "espiritualidade/filosofia" na apropriação que os professores de yoga franceses e suíços fazem, motivados por demandas de consumidores europeus contemporâneos por ensinamentos reclinados à superação de si (associados a uma prática corporal/esportiva) e, ao mesmo tempo, conhecimento e experiencias espiritualizados e filosóficos. Para se manter nesse mercado, os professores legitimam-se através de cinco estratégias: (1) afiliar-se à origem; (2) manter um tipo físico magro, forte e flexível; (3) seguir um estilo de vida disciplinado e saudável; (4) demonstrar conhecimento de "textos canônicos" da yoga; e (5) aproximar-se do estereótipo ascético do yogi. A autora conclui que duas posições opostas estão presentes nessa forma de significar a yoga na Europa: uma associada ao desenvolvimento pessoal através de práticas mais corporais e outra relacionada ao imaginário do yogi espiritual e filosófico do yoga autêntico, ambas as formas entendidas como respostas aos valores impostos pela cultura ocidental atual.

No último, mas não menos interessante artigo, Giovanni Cirino descreve as formas através das quais skatistas produzem e se apropriam de "vídeos de skate" e assim colaboram para a democratização global das técnicas corporais dos skatistas. A dinâmica específica de elaboração, divulgação e apropriação dos vídeos pelo skatistas é entendida pelo antropólogo como um processo performático que propicia um ambiente rico para a "imaginação" de mundos possíveis que se realizam nas diversas localidades do globo.

Celso de Brito, Daniel Granada, Matheus do Monte Marques e Ricardo Nascimento assinam a entrevista concedida por um dos maiores responsáveis pela divulgação da cultura afrobrasileira pelo mundo, Dr. Cinézio Peçanha, conhecido pela alcunha de Mestre Cobrinha Mansa. Dr. Cinézio ou Mestre Cobrinha formou o primeiro grande grupo transnacional de capoeira angola, tornando-se responsável por núcleos fixados nos cinco continentes. Nesta entrevista, ele nos conta parte de sua experiência no processo de transnacionalização da capoeira, tanto como capoeirista quanto como pesquisador. 
Ao entrar em contato com intelectuais africanos e africanistas, em meio às suas frequentes viagens pelo mundo, desenvolveu conceitos que se materializaram em produções intelectuais, sobretudo em sua tese de doutorado intitulada Gingando na linha da Kalunga: Capoeira Angola, Engolo e a construção da Ancestralidade, defendida em 2019 no Programa Multiinstitucional e Multidisciplinar em Difusão do Conhecimento da Universidade Federal da Bahia.

E, por fim, Luiz Gustavo Mendel Souza contribui com a resenha do livro Capoeira, mobility, and tourism: preserving an Afro-Brazilian tradition in a globalized world, de Sergio Varela. O livro aborda a formação de grupos de capoeira fora do Brasil e de como isso tem promovido uma circularidade turística em torno da capoeira angola, que altera conceitos fundamentais dessa prática, como a "tradição", a "afro-brasilidade" e a "ancestralidade". Algumas dessas alterações dizem respeito à instanciação da capoeira e de sua consequente incorporação às tradições dos locais de destino, como no México, onde a capoeira se imiscui a práticas neo-xamânicas, danças neo-astecas e figuras políticas míticas como Emiliano Zapata.

Ao artista plástico Fernando Mendonça, somos gratos pelas imagens, usadas na capa, de sua recente produção em aquarela chamada "Máscaras".

Desejamos a todas e todos uma proveitosa leitura e esperamos que venham dias melhores para voltarmos a celebrar os encontros e as trocas transnacionais! 